\title{
Article
}

\section{Comparison of Views of the Nature of Science between Natural Science and Nonscience Majors}

\author{
Marie C. Desaulniers Miller, ${ }^{*}$ Lisa M. Montplaisir, ${ }^{*}$ Erika G. Offerdahl, ${ }^{\dagger}$ \\ Fu-Chih Cheng, ${ }^{\ddagger}$ and Gerald L. Ketterling ${ }^{\S}$
}

Departments of ${ }^{*}$ Biological Sciences, ${ }^{+}$Chemistry and Molecular Biology, and ${ }^{\ddagger}$ Statistics, and ${ }^{\S}$ School of Education, North Dakota State University, Fargo, ND 58108-6050

Submitted May 13, 2009; Revised December 9, 2009; Accepted December 20, 2009

Monitoring Editor: Erin Dolan

\begin{abstract}
Science educators have the common goal of helping students develop scientific literacy, including understanding of the nature of science (NOS). University faculties are challenged with the need to develop informed NOS views in several major student subpopulations, including science majors and nonscience majors. Research into NOS views of undergraduates, particularly science majors, has been limited. In this study, NOS views of undergraduates in introductory environmental science and upper-level animal behavior courses were measured using Likert items and open-ended prompts. Analysis revealed similarities in students' views between the two courses; both populations held a mix of naïve, transitional, and moderately informed views. Comparison of pre- and postcourse mean scores revealed significant changes in NOS views only in select aspects of NOS. Student scores on sections addressing six aspects of NOS were significantly different in most cases, showing notably uninformed views of the distinctions between scientific theories and laws. Evidence-based insight into student NOS views can aid in reforming undergraduate science courses and will add to faculty and researcher understanding of the impressions of science held by undergraduates, helping educators improve scientific literacy in future scientists and diverse college graduates.
\end{abstract}

\section{INTRODUCTION}

\section{Scientific Literacy and Views of the Nature of Science}

Science educators have the common goal of helping students develop scientific literacy, which includes developing their foundational knowledge, critical-thinking skills, ability to apply what has been learned, and understanding of the nature of science (NOS) (American Association for the Advancement of Science [AAAS], 1991, 1993; Lederman, 1992; National Science Teachers Association, 2000, 2003). Not only can students' views of NOS influence their performance and learning in science courses, but they can also impact their interpretation of experiences and information throughout life-the degree of scientific literacy students develop in K-12 and postsecondary education affects personal, workplace, and community decisions (Driver et al., 1996; McCo-

DOI: $10.1187 /$ cbe.09-05-0029

Address correspondence to: (lisa.montplaisir@ndsu.edu). mas et al., 1998). Although there is no single, agreed-upon definition of NOS, there is a general consensus about the elements of NOS that should be included in science curricula (McComas and Olson, 1998). Reflective of this consensus, the elements of NOS that are the focus of this study are those that depict science and scientific knowledge as empirically based; subject to change; theory-laden; creative; subjective; and, as a human endeavor, influenced by society and culture (Abd-El-Khalick and Lederman, 2000; Lederman et al., 2002).

Most of the research on NOS views has focused on primary and secondary teachers and their students (Abd-ElKhalick, 2006; Ibrahim et al., 2009). It has been demonstrated that student and teacher views of NOS are frequently incongruent with more broadly accepted views of NOS (for review, see Lederman, 1992; Ryan and Aikenhead, 1992). National reform documents recommend the use of inquirybased professional development (for teachers) and science instruction (for students) to improve NOS views (AAAS, 1993; National Research Council, 1997). Although early re- 
search provides evidence that curriculum and teaching practices influence NOS views (Haukoos and Penick, 1983; Lederman and Druger, 1985; Lederman, 1986; Zeidler and Lederman, 1989), more recent work suggests that instructional approaches explicitly addressing NOS as an instructional outcome are more effective at promoting development of NOS conceptions (Khishfe and Abd-El-Khalick, 2002). Furthermore, explicitly reflective experiences were identified by Schwartz et al. (2004) as critical for the development of NOS views in preservice science teachers. Despite continued $\mathrm{K}-12$ investigations of the most effective methods for evaluating and improving NOS views, including developing curricula, enhancing pre- and in-service teacher training, and refining NOS instruments, there has been little work focused on student and teacher views of NOS at the undergraduate level (Abd-El-Khalick, 2006; Parker et al., 2008; Ibrahim et al., 2009).

\section{NOS Views in Undergraduate Education}

University faculties are challenged with the need to build scientific literacy and develop views of NOS in several major student subpopulations, including nonscience majors and science majors. Research into the education of these undergraduate students has been growing. Abd-El-Khalick (2006) examined the views of NOS of undergraduate and graduate students enrolled in a history of science course. These students came from a variety of majors, both science and nonscience. This study revealed that college students have similar NOS views to high school students; the majority of participants held naïve or inaccurate ideas about NOS.

In a more focused investigation of science versus nonscience majors, results from Liu and Tsai (2008) indicate that undergraduates' epistemological views of science do not differ significantly. In general, the level of sophistication of the two populations' views was equivalent. However, nonscience majors' views were more sophisticated than science majors' views with regard to the theory-laden and culturally dependent aspects of science. One hypothesis to explain this difference is the manner in which scientific processes and knowledge are presented in science classrooms. Often knowledge in these settings is depicted as universal and objective, thereby reinforcing a less-sophisticated view of NOS. Science majors may be exposed to such epistemic views for longer than students majoring in the humanities due to the nature of their course work.

A handful of studies have examined science majors' NOS views in particular. Parker et al. (2008) explored the views of atmospheric science students and found evidence suggesting that students view 1) science as empirically based (with emphasis on proving, finding facts, or arriving at right or wrong answers), 2) experiments as serving the role of testing or confirming scientific ideas, 3) a hierarchical relationship between laws and theories, and 4) creativity as an important aspect of science. Other studies of undergraduates within specific disciplines have revealed subtle differences in undergraduates' views of NOS that vary between disciplines (Dagher and BouJaoude, 1997; Bezzi, 1999). For example, Dagher and BouJaoude (1997) revealed that undergraduate biology majors' definitions of a scientific theory were associated with their dismissal of the theories used in field disciplines (i.e., biology and geology) as unscientific.
Other researchers have argued that current representations of NOS as articulated in documents informing science curricula (i.e., AAAS Benchmarks and National Science Education Standards) do not accurately reflect an authentic view of science from the perspective of those actually engaging in the enterprise. Most of these representations have resulted from the efforts of philosophers of science, science educators, science communicators, and science historians to characterize NOS. Few of these efforts have sought to include the views of practicing scientists. Recent work by Wong and Hodson (2009) revealed inconsistencies between the views held by scientists and those articulated in the science studies literature. Most notably, they cite evidence that scientists, similar to high school and college students, also articulate a hierarchical relationship between laws and theories and in some contexts describe science as universal. Given that scientists' views impact the context into which undergraduate science majors are acculturated, it may not be surprising, after all, that science majors often hold naïve views of NOS. Some have gone further to argue that because these "naïve" views have little impact on the day-to-day practices of scientists, perhaps the characterization of NOS views as naïve and sophisticated deserves a reexamination altogether (Elby and Hammer, 2001; Wong and Hodson, 2009).

\section{Research Questions}

Effective reform efforts to develop students' views of NOS and improve scientific literacy require a more complete picture of students' baseline NOS views; the factors that influence modification, replacement, or change of NOS ideas; and the effects of current and proposed teaching practices and other educational experiences on those NOS learning goals. As a first step toward this goal, the purpose of this study was to gain a clearer understanding of the NOS views of a sample of undergraduate students enrolled in two biology courses: environmental science (ES) designed to serve nonscience majors, and animal behavior (AB), an upperlevel biology course for natural science majors.

The study was shaped by the following research questions:

1. What are the NOS views of nonscience majors and natural science majors enrolled in undergraduate biology courses, and how do the views of these two groups compare?

2. In what ways, if any, do student NOS views change through these courses?

\section{METHODS}

\section{Context and Study Participants}

This study was conducted at a research 1 land-grant university with a student population of approximately 13,000. The sample consisted of volunteers from two undergraduate courses offered by the Department of Biological Sciences: ES and $\mathrm{AB}$. Instructors of both courses routinely include NOS instruction as part of their explicit course goals, and no specific intervention or alteration of this instruction was made as a part of this study. 
Environmental science is an introductory nonmajors course of 300 students with approximately half of the students concurrently enrolled in the laboratory course. Students explore key concepts in ecology and environmental science; learn to apply critical thinking to environmental issues; investigate the complexity, current status, and potential solutions to environmental problems; and contemplate the relationship between humans and their environment. NOS and connections to how people view and interpret environmental issues and data are presented early in the course. Differences between theories and laws are discussed along with the implication of how new information or ideas can change what is accepted by the science community.

$\mathrm{AB}$ is an upper-level course cross-listed between psychology and zoology ( 100 students). The course is designed to evaluate the evolutionary implications and foundations of animal behavior. The approach is integrative and students are expected to understand animal behavior from the proximate mechanisms to the ultimate causes. The NOS is explicitly discussed early in the course, emphasizing the processes of science, what constitutes evidence, and how data are collected. Several in-class lab exercises are used to reinforce the process of data collection and analysis. For example, students conduct an experiment to evaluate optimal foraging theory, in which they test several assumptions of the theory, collect data using a naïve classmate as a forager, and analyze the data. The NOS is an underlying theme throughout the course with explicit exercises used to reinforce the scientific process and illustrate the development of scientific theory.

\section{Data Collection}

Undergraduate students in an ES course were given the Student Understanding of Science and Scientific Inquiry (SUSSI) questionnaire (Liang et al., 2008; initially accessed in C. Liang, K. Chen, E. Macklin, unpublished data) during the first and last week of fall semester 2007. Students in AB were given the SUSSI questionnaire in the first and last weeks of spring semester 2008.

The SUSSI questionnaire (Liang et al., 2008) is an instrument designed with both Likert-scale and open-ended components, to provide opportunities for in-depth study of NOS views (as emphasized in the Views of the Nature of Science [VNOS]; Lederman et al., 2002) while retaining the efficiency of previous forced-choice instruments (many used over the past 55 years, such as the Science Attitudes Questionnaire [Wilson, 1954], the Test on Understanding Science [Klopfer and Cooley, 1961], the Science Process Inventory [Welch and Pella, 1967], the Nature of Science Test [Billeh and Hassan, 1975], the Nature of Scientific Knowledge Scale [Rubba and Andersen, 1978], the Conceptions of Scientific Theories Test [Cotham and Smith, 1981], and the Views on Science-Technology-Society instrument [Aikenhead et al., 1989]). The SUSSI questionnaire is composed of sections to measure six aspects of NOS views: a) Observations \& Inferences, b) Change of Scientific Theories, c) Scientific Laws versus Theories, d) Social \& Cultural Influences on Science, e) Imagination \& Creativity in Scientific Investigations, and f) Methodology of Scientific Investigation. Each section includes three to four Likert-scale items and a short-answer prompt asking students to explain their view of a particular aspect of science or scientific research using examples.

The SUSSI questionnaire was developed for use with undergraduates and was revised and tested for reliability and validity by Liang et al. (2008). Reported Cronbach's alpha values for the six sections of the instrument ranged from a low of 0.44 to a high of 0.89 . Development of the SUSSI questionnaire also incorporated analysis of student interpretation of Likert-scale items and the degree of consistency between Likert-scale and open-ended responses.

\section{Data Analysis}

Student responses to Likert-scale items were coded with numerical values, with a score of 5 representing the most informed view of NOS and a score of 1 the least informed view. Mean scores for each component and the overall SUSSI instrument were calculated. For each class, pre- and posttest Likert scores were analyzed using multivariate analysis of variance (MANOVA) to test the null hypothesis. This was followed by use of Sidak multiple comparison method for pairwise comparisons to investigate mean differences between pre- and posttest scores for all pairs of six SUSSI aspects, using SAS version 9.1 (SAS Institute, Cary, NC) as suggested by Westfall et al. (1999). Partial eta ${ }^{2}$ values were calculated for all MANOVAs as described by Steyn and Ellis (2009). Students who did not complete both a preand postcourse SUSSI questionnaire were dropped from this aspect of analysis (181 complete SUSSI sets from 265 participants in ES [68.3\%]; 50 complete SUSSI sets from 86 participants in $\mathrm{AB}[58.1 \%])$.

Student responses to the open-ended portion of the SUSSI questionnaire were collected except on the ES posttest, due to in-class time limitations. Student open-ended responses were scored using the SUSSI rubric provided by Liang (personal communication) and described in Table 1, categorizing responses as informed (score of 3), transitional (2), naïve (1), or not classifiable (0), as developed by Liang et al. (2009). The first and second authors scored the open-ended responses independently, beginning with a set of SUSSI questionnaires randomly selected from ES and $\mathrm{AB}$ pretests. They first independently coded $\sim 300$ of the submitted responses and had an interrater reliability of $71.6 \%$. To seek a higher level of reliability, they then met to compare their coding decisions. Careful examination and discussion of instances of discrepant codings resulted in further refinement and finalization of the interpretation of the coding rubric, leading to an interrater reliability of $82.2 \%$ on the next 360 coded items. The remaining SUSSIs were scored primarily by the first author, who sought affirmation from the second author on any responses that were difficult to interpret or classify ( $<15 \%$ of the responses).

These data were analyzed through calculations of the frequency of each score $(0,1,2$, or 3$)$ within each of the six aspects by class pre- or posttest. These frequency measures were reported as the percentage of students in each group to have received each score. A comparison of pre- and posttest mean open-ended scores was also made using the mean score test statistic $(\mathrm{Q})$, approximately a chi-square test statistic, of the Cochran-Mantel-Haenszel method, as suggested by Stokes et al. (2000). This is a repeated measures analysis for categorical data used to test the null hypothesis 
Table 1. Rubric for scoring SUSSI open responses developed from Liang et al. (2009)

\begin{tabular}{|c|c|c|c|c|}
\hline Question & Not classifiable & Naïve view (1) & Transitional view (2) & Informed view (3) \\
\hline $\begin{array}{l}\text { With examples, } \\
\text { explain why } \\
\text { you think } \\
\text { scientists' } \\
\text { observations } \\
\text { and } \\
\text { interpretations }\end{array}$ & $\begin{array}{l}\text { There is no response; } \\
\text { they state that they } \\
\text { do not know; the } \\
\text { response does not } \\
\text { address the } \\
\text { prompt; OR the } \\
\text { response cannot be }\end{array}$ & $\begin{array}{l}\text { Scientists' observations } \\
\text { AND/OR } \\
\text { interpretations are } \\
\text { the same because } \\
\text { scientists are } \\
\text { objective. } \\
\text { OR }\end{array}$ & $\begin{array}{l}\text { Scientists' observations OR } \\
\text { interpretations may be } \\
\text { different because of their prior } \\
\text { knowledge, personal } \\
\text { perspective, or beliefs. } \\
\text { OR } \\
\text { The observations AND/OR }\end{array}$ & $\begin{array}{l}\text { Scientists' observations AND } \\
\text { interpretations may be } \\
\text { different because of their } \\
\text { prior knowledge or } \\
\text { perspectives in current } \\
\text { science. }\end{array}$ \\
\hline
\end{tabular}

2. With examples, There is no response; explain why you think scientific theories do not change OR how (in what way) scientific theories change.

3. With examples, explain the nature of and difference between theories and scientific laws.

4. With examples, explain how society and culture affect OR do not affect scientific research.

5. With examples, explain why scientists do not use imagination and creativity OR how and when they use imagination and creativity. they state that they do not know; the response does not address the prompt; OR the response cannot be classified based on the rubric descriptions.

There is no response; they state that they do not know; the response does not address the prompt; OR the response cannot be classified based on the rubric descriptions.

There is no response; they state that they do not know; the response does not address the prompt; OR the response cannot be classified based on the rubric descriptions.

There is no response; they state that they do not know; the response does not address the prompt; OR the response cannot be classified based on the rubric descriptions.
The response includes misconceptions concerning the nature of science or selfcontradicting statements.

Scientific theories do not change over time if they are based on accurate experiments or facts.

OR

e observations AND/OR interpretations may be different, but failed to provide reasons for justification.

The response includes misconceptions concerning the nature of science or selfcontradicting statements.

Scientific laws are more Scientists FIND theories or laws certain than theories, in nature. or theories become laws when they are proven.

OR

sponse include misconceptions concerning the nature of science or selfcontradicting statements.

Science is a search for universal truth and fact which is not affected by culture and society.

OR

The response includes misconceptions concerning the nature of science or selfcontradicting statements.

Scientists do not use imagination or creativity because imagination and/or creativity are in conflict with objectivity.

OR

The response includes misconceptions concerning the nature of science or selfcontradicting statements. problem solving.
Scientific theories may be changed when experimental techniques improve, or new evidence is produced.

The student provides valid example(s) of scientific laws and theories without further elaboration.

Scientific theories may also be changed when existing evidence is reinterpreted.

Scientific theories are wellsubstantiated explanations of natural phenomena or scientific laws.

AND

Both scientific laws and theories are subject to change.

Scientists are informed by their culture and society. Culture determines what OR how science is conducted, or accepted.

OR

The student simply states that science is influenced by cultural and society without further elaboration.

Scientists use their imagination or creativity in SOME phases of their work, notably in designing experiments or
Scientists are informed by their culture and society. Culture determines what AND how science is conducted, or accepted.

Scientists use their imagination or creativity throughout their scientific investigations. 


\begin{tabular}{|c|c|c|c|c|}
\hline Question & Not classifiable & Naïve view (1) & Transitional view (2) & Informed view (3) \\
\hline $\begin{array}{l}\text { 6. With examples, } \\
\text { explain whether } \\
\text { scientists follow } \\
\text { a single, } \\
\text { universal } \\
\text { scientific } \\
\text { method OR use } \\
\text { different types } \\
\text { of methods. }\end{array}$ & $\begin{array}{l}\text { There is no response; } \\
\text { they state that they } \\
\text { do not know; the } \\
\text { response does not } \\
\text { address the } \\
\text { prompt; OR the } \\
\text { response cannot be } \\
\text { classified based on } \\
\text { the rubric } \\
\text { descriptions. }\end{array}$ & $\begin{array}{l}\text { There is a single, } \\
\text { universal, or step-by- } \\
\text { step scientific method } \\
\text { that should be used. } \\
\text { OR } \\
\text { The response includes } \\
\text { misconceptions } \\
\text { concerning the nature } \\
\text { of science or self- } \\
\text { contradicting } \\
\text { statements. }\end{array}$ & $\begin{array}{l}\text { Scientists may use } \\
\text { different methods, but } \\
\text { their results must be } \\
\text { confirmed by the } \\
\text { scientific method or } \\
\text { experiments. } \\
\text { OR } \\
\text { Student states that } \\
\text { scientists use different } \\
\text { methods without } \\
\text { providing any } \\
\text { justification or examples. }\end{array}$ & $\begin{array}{l}\text { There is no single, universal } \\
\text { step-by-step scientific } \\
\text { method that all scientists } \\
\text { follow. Scientists use a } \\
\text { variety of valid methods } \\
\text { (e.g., observation, } \\
\text { mathematical deduction, } \\
\text { speculation, library } \\
\text { investigation, and } \\
\text { experimentation). }\end{array}$ \\
\hline
\end{tabular}

that there is no association of pre- and posttest mean openended scores for each of the six SUSSI components. A test statistic (Q) with a $p$ value below $5 \%$ would provide evidence for a significant difference between mean student scores on the pre- and posttests.

To analyze change in NOS views of $A B$ students, it was necessary to examine and account for correlation in student responses on all six aspects. Therefore, a univariate repeated measures analysis was used. In considering within-subject variability in the analysis, it was not reasonable to assume equal variances across multiple items on each component of pre- and posttests, so heterogeneous linear mixed models were incorporated, as described by Westfall et al. (1999). In evaluating correlations with this mixed model approach, student open-ended scores were analyzed as a covariate to Likert scores. Post hoc multiple comparisons (TukeyKramer method) of the six components were conducted to test the null hypothesis that there is no difference between student scores on each section of the SUSSI questionnaire.
These comparisons were used to determine whether there were significant correlations between students' views of the six different aspects of NOS measured by the SUSSI questionnaire.

\section{RESULTS}

\section{Analysis of SUSSI Data}

An illustration of ES and AB students' NOS views is found in Figure 1. Mean Likert scores from the ES SUSSI tests show that students had more informed views of Scientific Theories (b) and Observations \& Inferences (a); less informed views of Social \& Cultural Influences (d), Imagination \& Creativity (e), and Methodology of Science (f); and uninformed views of Laws versus Theories (c). Mean scores on the Laws \& Theories (c) component were notably lower than mean scores on the other five components. Overall pattern of mean scores on the six aspects was similar between the two

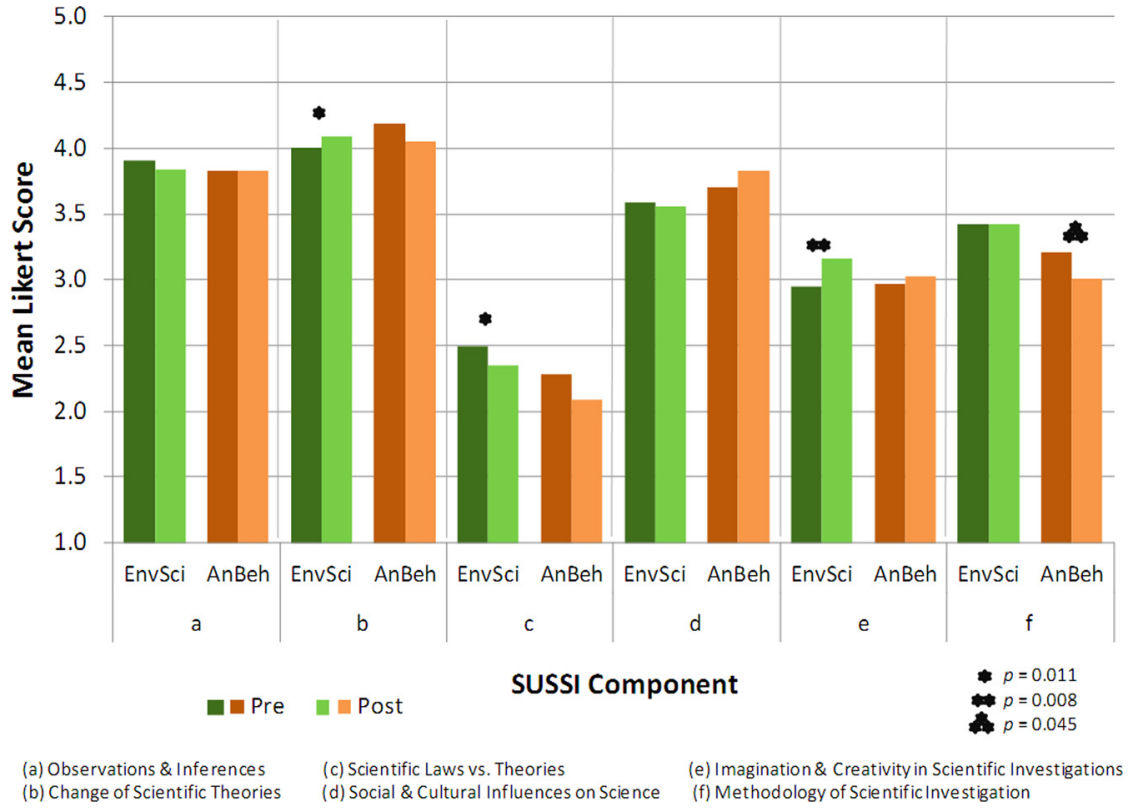

Figure 1. Comparison of student views of NOS before and after ES and $\mathrm{AB}$ courses based on mean Likert scores. 
Table 2. Standardized Cronbach's alpha values for overall SUSSI questionnaire and six components in ES and AB courses

\begin{tabular}{|c|c|c|c|c|}
\hline \multirow[b]{3}{*}{ SUSSI component section } & \multicolumn{4}{|c|}{ Cronbach's alpha value } \\
\hline & \multicolumn{2}{|c|}{ Environmental science } & \multicolumn{2}{|c|}{ Animal behavior } \\
\hline & Pretest & Posttest & Pretest & Posttest \\
\hline Overall SUSSI & 0.751 & 0.760 & 0.612 & 0.831 \\
\hline (a) Observations \& Inferences & 0.560 & 0.580 & 0.454 & 0.692 \\
\hline (b) Change of Scientific Theories & 0.652 & 0.611 & 0.536 & 0.736 \\
\hline (c) Scientific Laws vs. Theories & 0.451 & 0.371 & 0.307 & 0.419 \\
\hline (d) Social \& Cultural Influences on Science & 0.635 & 0.578 & 0.743 & 0.816 \\
\hline (e) Imagination \& Creativity in Scientific Investigations & 0.868 & 0.857 & 0.778 & 0.840 \\
\hline (f) Methodology of Scientific Investigation & 0.343 & 0.231 & 0.266 & 0.567 \\
\hline
\end{tabular}

courses; however, mean scores of $\mathrm{AB}$ students on both the pre- and posttests were lower than corresponding ES preand posttest mean scores on Laws versus Theories (c) and Methodology of Science (f) and higher on Social \& Cultural Influences (d).

MANOVA analysis of the Likert-scale SUSSI scores of ES and $A B$ students indicated that at least one of six SUSSI aspects' pre- and posttest mean score pairs is statistically different at the $5 \%$ level of significance (Figure 1). ES Wilks' lambda value $=0.837, F(6,174)=5.65, p<0.001$ and partial eta $^{2}=0.271$ and AB Wilks' Lambda value $=0.725, F(6,44)=$ $2.78, p=0.022$ and partial eta ${ }^{2}=0.436$. Further analysis of the differences between pre- and posttest mean scores in ES of each of the six aspects using the Sidak multiple comparison method showed a significant increase in scores for Scientific Theories (b) ( $p=0.011)$ and Imagination \& Creativity (e) $(p=0.008)$, and a significant decrease in scores for Laws versus Theories (c) $(p=0.011)$. Analysis of the AB students' scores using the Sidak multiple comparison method indicated a significant decrease in posttest scores compared with pretest scores for Methodology of Science (f) $(p=0.045)$. Standardized Cronbach's alpha values are shown in Table 2.
Student scores on the open-ended portion of the pretest show trends similar to the mean Likert results (Figure 2). The highest percentage of ES student responses earned a score of 1 on Laws versus Theories (c) followed by Methodology of Science (f), two of the three components on which students earned the lowest mean Likert scores. No student earned a score of 3 on Laws versus Theories (c), whereas approximately $75 \%$ of students earned a score of 2 or 3 on Observations \& Inferences (a) and Social \& Cultural Influences (d). AB student scores reflect general trends evident in the ES course results. On both pre- and posttests the highest percentage of students earned naïve scores on Laws versus Theories (c) followed by Methodology of Science (f), with the highest percentage of informed scores earned on the Observations \& Inferences (a) pretest and the Social \& Cultural Influences (d) posttest. Changes in written response scores from pretest to posttest by component were mixed, with a higher frequency of transitional or informed scores on some posttest SUSSI components but not others. CochranMantel-Haenszel testing of pre- and posttest mean openended scores showed a significant decrease in mean score after the $\mathrm{AB}$ course compared with before on the Observations \& Inferences (a) component $(\mathrm{Q}=8.462, \mathrm{df}=3, p=$ 0.037 ). Differences between pre- and posttest mean open-
Figure 2. Comparison of student views of NOS before and after ES and $\mathrm{AB}$ courses based on written response scores.

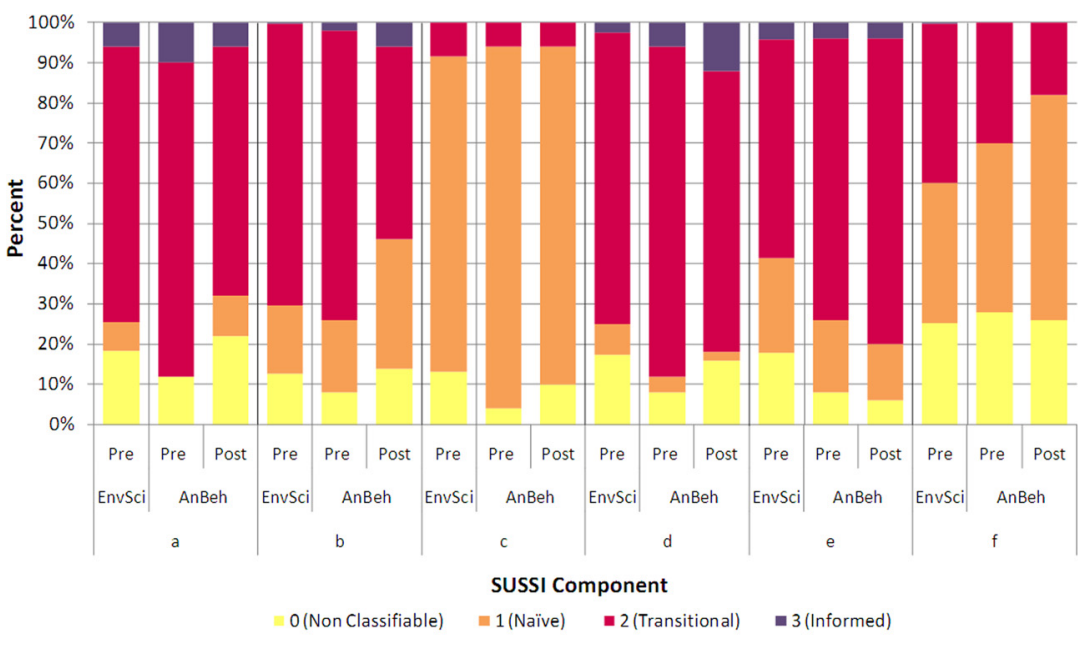

(a) Observations \& Inferences (b) Change of Scientific Theories (c) Scientific Laws vs. Theories (d) Social \& Cultural Influences on Science (e) Imagination \& Creativity in Scientific Investigations (f) Methodology of Scientific Investigation 
Table 3. SUSSI component comparisons found not to show a difference $^{a}$

\begin{tabular}{lcc}
\hline & Comparison & Adjusted $p$ value \\
\hline $\begin{array}{l}\text { Environmental science } \\
\text { Combined }\end{array}$ & & \\
Pretest & $\mathrm{d}-\mathrm{f}$ & 0.469 \\
$\quad$ Posttest & $\mathrm{d}-\mathrm{f}$ & 0.144 \\
Animal behavior & & \\
Combined & $\mathrm{a}-\mathrm{d}$ & 0.352 \\
& $\mathrm{e}-\mathrm{f}$ & 0.851 \\
Pretest & $\mathrm{a}-\mathrm{d}$ & 0.115 \\
& $\mathrm{e}-\mathrm{f}$ & 0.162 \\
Posttest & $\mathrm{a}-\mathrm{b}$ & 0.124 \\
& $\mathrm{a}-\mathrm{d}$ & 1.000 \\
& $\mathrm{~b}-\mathrm{d}$ & 0.096 \\
& $\mathrm{e}-\mathrm{f}$ & 0.956
\end{tabular}

a All other comparisons were significantly different at the $p \leq 0.050$ level, many at $p<0.001$.

ended scores on the other five components were not significant $(p>0.050)$. On the SUSSI pretests, AB students tended to receive higher open-ended scores more frequently than ES students, most notably on Observations \& Inferences (a), Social \& Cultural Influences (d), and Imagination \& Creativity (e). On Methodology of Science (f), ES students more frequently earned transitional scores than $\mathrm{AB}$ students.

Univariate repeated measures analysis showed a strong correlation between student scores on the open-ended questions and Likert-scale items in both courses $(p<0.001)$. Further analysis using the square of open-ended scores indicated that the correlation is nonlinear $(p<0.001)$. Accounting for this correlation, there was no evidence of difference between overall (combined Likert-scale and open-ended) scores on pre- and posttests in AB.

When mean combined Likert and open-ended scores on the six SUSSI components were compared with each other (a to $b$, a to $c$, a to $d$, and so on) using the Tukey-Kramer adjustment, a significant difference was found for all comparisons of combined, pre-, and posttest scores for each course $(p \leq 0.050)$ except for those indicated in Table 3 .

\section{SUSSI Written Responses}

Written responses to open-ended prompts (Table 1) provided additional evidence of student views of NOS. Student responses to the prompt for Laws versus Theories (c) showed that many of them held the naïve view that with enough evidence theories will become laws and that scientists are able to "prove" scientific explanations or natural phenomena. These responses were interpreted as evidence that students are able to identify valid examples of scientific theories and laws and understand some aspects of the scientific process (e.g., "tested and retested"), but may maintain naïve views of the differences between laws and theories as well as naïve or transitional ideas about the balance of empiricism and tentativeness in building scientific knowledge.

Although student responses were more frequently coded as transitional and informed for the Scientific Theories (b) prompt than the Laws versus Theories (c) prompt, these responses also revealed common naïve views of scientific theories. For example, student responses showed a blurring of the distinctions between scientific hypotheses and theories, possibly conflating the vernacular use of the word "theory" with their understanding of hypotheses. Some student responses, particularly to the Methodology of Science (f) prompt, seemed to show misinterpretation of the prompt that led to a high frequency of nonclassifiable scores on this component and difficulty in determining student views on the aspect of NOS this section was designed to address. On some components, the written responses illustrated a more diverse array of student views than on others. This was evident in Imagination \& Creativity (e), where student views ranged from describing the use of imagination and creativity in science as fraudulent and unethical to essential to progress and applicable throughout the scientific process, with a wide range of transitional ideas.

Results from the open-ended data analysis align with emergent themes from the analysis of Likert-scale items, namely that 1) written responses to the prompt for laws versus theories revealed naïve views and 2) views elucidated about scientific theories were more sophisticated than laws versus theories. However, an analysis of written responses indicates that students interpret some of the prompts in the instrument inconsistently and frequently draw on examples from the media and course work when articulating their NOS views. Finally, written responses demonstrated the nature of growth in individual students' NOS views.

\section{DISCUSSION AND IMPLICATIONS}

Results from this study provide evidence that undergraduate students in ES and AB have similar views of NOS, ranging on average from naïve to somewhat informed. Based on mean SUSSI scores, changes in NOS views were only significant in select aspects of NOS, and these were split between changes toward more and less informed NOS views. Very few studies have examined NOS views of students within specific disciplines. The results discussed here are significant in that they corroborate findings from studies of science majors in other disciplines (Bezzi, 1999, Parker et al., 2008). This study looked specifically at biology majors and supports an emerging trend that although there may be nuances among the disciplines, there are larger trends in NOS views among science majors in general.

This work is significant in that it invites further thought about how NOS views can be measured in larger populations. In particular, it provides insight into the complexity and challenges involved in measuring and interpreting student NOS views. Although the Likert portion of the SUSSI provides an advantage over other exclusively open-ended instruments such as the VNOS, difficulties in analysis of the short-answer items suggest further modification of the SUSSI scoring rubric to include a finer scale of characterization. This might reveal subtle but relevant differences in NOS views between students as well as changes in the views of individual students over time. 


\section{Research Question 1: NOS Views of Nonscience and Science Majors}

Both the open-ended response and Likert data from the six SUSSI components show that all participants simultaneously hold informed and naïve views of some aspects of NOS. In particular, open-ended and Likert data indicate relatively informed student views of Scientific Theories (b), yet relatively uninformed views of the distinction between scientific theories and laws, consistent with results from previous studies (e.g., Parker et al., 2008). This apparent contradiction highlights the complexity of NOS, and may indicate that students have only a surface-level understanding of the NOS concepts addressed in class or experience ongoing difficulty with scientific terminology.

A comparison of mean Likert scores between natural science majors and nonscience majors reveals striking similarity on several SUSSI components, specifically Observations \& Inferences (a), Scientific Theories (b), and Imagination \& Creativity (e). This similarity raises questions about what factors might influence the NOS views of students with varied science backgrounds and experiences. Observations \& Inferences (a) and Scientific Theories (b) are the two sections on which students in both classes earned the highest mean Likert scores. It is possible that both science majors and nonscience majors tend to have informed views of observations and inferences (reflecting that a scientist's observations and interpretations are different from those of another scientist) because of their general experiences working with others in a variety of situations. Undergraduate students may have a more informed view of this part of NOS compared with younger students because of experience and developmental level. It is also possible that certain types of naïve views remain hidden in student responses to the Scientific Theories (b) Likert questions. Mean scores from both groups reflect transitional views reflecting the belief that scientists use imagination and creativity for some aspects of research (developing hypotheses and designing experiments) but should not use them for other aspects of research (data collection, analysis, and interpretation). Perhaps some upper-level science majors such as those in $A B$ still have such limited experience with authentic research and inquiry processes that they maintain similar views to students in an introductory course such as ES.

One noticeable difference between the two populations was on SUSSI components $\mathrm{c}$ and $\mathrm{f}$, which address the distinction between scientific theories and laws and the diverse methods of scientific research. Here, the AB mean pre- and posttest Likert scores were lower than the ES scores. This is surprising given that one might expect more informed NOS views in natural science majors, particularly by the time they are in upper-level courses, due to both increased experience and assumed interest in science. These findings are consistent with previous work by Liu and Tsai (2008), who propose two interpretations of this discrepancy. Natural science students' NOS views might be explained by their learning experiences. Participation in science courses that often portray scientific knowledge and processes as universal and objective might have a negative impact on NOS views. Alternatively, it is possible that a student's initial beliefs about certainty and objectivity might cause the student to select a major in science. Course work for science majors might reflect a stronger focus on other aspects of scientific literacy, such as foundational knowledge and the ability to apply this knowledge, compared with other NOS objectives.

Written response scores on the SUSSI questionnaire seem to corroborate the Likert item findings. Overall, ES and AB students have similar score frequencies, although in some cases $\mathrm{AB}$ students were better able to provide appropriate examples in support of their responses. On average, students scored higher in the written responses than the Likert items in component (d) regarding the Social \& Cultural Influences on science, whereas the students' open-ended scores were lower on Scientific Theories (b) and Methodology of Science (f) relative to frequencies of scores on other components in comparison to mean Likert score distribution across the six components. Given the correlation between students' responses to the Likert-scale and open-response items, it is possible that with larger populations one could use just the Likert items to elucidate a broad picture of students' NOS views.

\section{Research Question 2: Changes in NOS Views of Undergraduates}

As measured by Likert-scale items on the SUSSI questionnaire, overall student views of NOS did not improve consistently over the course of the ES class, however, there was improvement in mean scores for Scientific Theories (b) and Imagination \& Creativity (e). Along with the generally low scores in the Laws versus Theories (c) section discussed above, it may concern educators that mean Likert scores for this section showed a significant decrease from pre- to posttest. It is not clear what contributed to this shift toward less informed views, and educators could benefit from further study of this type of change.

Analysis also revealed a significant decrease in informed views of Observations \& Inferences (a) and Methodology of Science (f) for AB students. A consistent pattern of improvement in NOS views throughout the AB course was not apparent in the frequency of response scores, at least in terms of students' ability to explain their views in openended form on the SUSSI questionnaire. Although the mean scores for Observations \& Inferences (a) were not low relative to scores on other sections, the significant decrease in mean open-ended scores for AB students on this section was surprising. Students were involved in activities requiring them to make observations, develop hypotheses, test them, and interpret their results. However, it seems that experiences such as these did not lead to more informed views in some students. Furthermore, it seemed that some students were limiting their thinking to certain fields of experimental science and focused only on clearly quantitative measurements.

The low scores on Methodology of Science (f), apparent in the high percentage of naïve scores by $\mathrm{AB}$ students, are also noteworthy. Many students focused on experimental protocols rather than on the types of investigational approaches used in wide-ranging scientific disciplines. These results indicate that faculty attempting to expand student views of the diversity in scientific methodology may face long-held student ideas about the "scientific method." Some AB students addressed their confusion directly by including references to texts and both previous and ongoing science course 
experiences. Student experience of research methodology was limited in both courses despite inclusion of inquiry activities modeling aspects of scientific investigation and examples of professional scientific research relevant to course content topics. This suggests that overcoming years of instruction depicting the empirical foundation of science as rigid or unidirectional will probably take more than isolated class activities to overcome.

\section{Study and Instrument Limitations}

Frequencies of open-ended scores for all six aspects reflect challenges in using the SUSSI and similar instruments to study student NOS views. For example, the coding as nonclassifiable (0) within each component for the subgroups is large. Nonclassifiable is represented when students did not complete a particular question (1), students indicated they did not know an answer (2), the meaning of student writing was unclear (3), or the writing did not address the intended topic (4). For example, student written responses to Methodology of Science (f) at times were unclear in terms of whether students were referring to experimental protocols or wider issues of methodology. Student writing skills and attention to the task both influence the ability of researchers to interpret and use their responses.

Scoring of open-ended responses was complicated by the three-level naïve-transitional-informed scale which at times did not fully reflect the subtlety of differences in student NOS views. For example, some responses to the prompt for Laws versus Theories (c) classified as naïve seemed to indicate views moving toward what would be classified as transitional, whereas others showed no evidence of this development. On other components, such as Scientific Theories (b), very few student responses were classified as informed, partially due to the lack of an explicit mention of data reinterpretation. It is unclear whether this was effectively differentiating transitional and informed views, as students may not think to comment on reinterpretation if not directly prompted. Focused interviews of select students would aid in interpretation of open-ended responses. Finally, the use of transitional as a category raised concern. The term transitional may imply students' responses could move from naïve to informed in an interval step. Rather, the views represented a mix of ideas (as described by Sandoval, 2005) as opposed to a progression of ideas.

Much research has focused on potential changes in NOS views through specific learning activities or courses. This study and others have shown changes in views of only a few aspects of NOS during these short time frames (A. Adams, M. Macklin, P. Christol, S. Willingham, V. Hurst, M. Underwood, unpublished data), including changes toward more naïve views. This may be an indication that the development of NOS views is a long-term process influenced by a variety of factors. Researcher and instructor understanding of the development of student NOS views would benefit from further longitudinal studies examining view formation and change over the course of undergraduate degree. Expansion of the open-response scoring rubric to include finer characterization of responses would reveal changes in students' thinking over that time frame. Researchers might then be able to address whether students' naïve views are a result of acculturation to a context reinforced by scientists holding similarly naïve views (Wong and Hodson, 2009) or result from a lack of understanding in general.

Science departments play an important role for undergraduate science majors and nonmajors in a heavily scienceand technology-based society. Data contributing to an increased understanding of the NOS views of undergraduate science students and student response to efforts to improve NOS views have a clear utility to department faculties seeking to refine course goals and reform course offerings, content, and methodology to more effectively serve varied student subpopulations. These instructors-frequently under considerable pressure with limited time, many students, and high expectations-confront the challenge of balancing literacy priorities and can use this and other research evidence as guidance for determining areas of focus and effective methodology. In addition to using research findings to refine literacy goals and plans to meet them, instructor use of NOS views instruments such as the SUSSI questionnaire as formative tools could be greatly expanded. Use of these instruments could improve faculty and student awareness of student NOS views and provide opportunity for discussion of NOS and reflection on the processes of scientific inquiry and investigation.

\section{ACKNOWLEDGMENTS}

We thank colleague W. Reed and students who have participated in and supported this project (Institutional Review Board protocol SM08012) without whose participation this study could not have been conducted, as well as L. Liang for providing the SUSSI openended scoring rubric. This study was funded in part by National Science Foundation grants DGE 0338128 and HRD 0811239. Any opinions, findings, and conclusions or recommendations expressed are those of the authors and do not necessarily reflect the views of the National Science Foundation.

\section{REFERENCES}

Abd-El-Khalick, F. (2006). Over and over again: college students' views of nature of science. In: Scientific Inquiry and Nature of Science: Implications for Teaching, Learning, and Teacher Education, ed. L. B. Flick and N. G. Lederman, Dordrecht, The Netherlands: Kluwer Academic Publishers, 389-426.

Abd-El-Khalick, F., and Lederman, N. G. (2000). Improving science teachers' conceptions of the nature of science: a critical review of the literature. Int. J. Sci. Educ. 22, 665-701.

Aikenhead, G. S., Ryan, A. G., and Fleming, R. W. (1989). Views on Science-Technology-Society (form CDN.mc.5), Saskatoon, Canada: Department of Curriculum Studies, University of Saskatchewan.

American Association for the Advancement of Science (AAAS) (1991). Science for All Americans, New York: Oxford University Press. www.project2061.org/publications/sfaa/online/sfaatoc.htm (accessed 10 March 2009).

AAAS (1993). Benchmarks for Science Literacy, New York: Oxford University Press.

Bezzi, A. (1999). What is this thing called geosciences? Epistemological dimensions elicited with the repertory grid and their implications for scientific literacy. Sci. Educ. 83, 675-700.

Billeh, V. Y., and Hassan, O. E. (1975). Factors affecting teachers' gain in understanding the nature of science. J. Res. Sci. Teach. 12, 209-219. 
Cotham, J. C., and Smith, E. L. (1981). Development and validation of the conceptions of scientific theories test. J. Res. Sci. Teach. 18, 387-396.

Dagher, Z. R., and BouJaoude, S. (1997). Scientific views and religious beliefs of college students: the case of biological evolution. J. Res. Sci. Teach. 24, 429-445.

Driver, R., Leach, J., Millar, R., and Scott, P. (1996). Young People's Images of Science, Bristol, PA: Open University Press.

Elby, A., and Hammer, D. (2001). On the substance of a sophisticated epistemology. Sci. Educ. 85, 554-567.

Haukoos, G. D., and Penick, J. A. (1983). The influence of classroom climate on science process and content achievement of community college students. J. Res. Sci. Teach. 20, 629-637.

Ibrahim, B., Buffler, A., and Lubben, F. (2009). Profiles of freshman physics students' views on the nature of science. J. Res. Sci. Teach. $46,248-264$

Khishfe, R., and Abd-El-Khalick, F. (2002). Influence of explicit and reflective versus implicit inquiry-oriented instruction on sixth graders' views of nature of science. J. Res. Sci. Teach. 39, 551-578.

Klopfer, L., and Cooley, W. (1961). Test on Understanding Science. Form W, Princeton, NJ: Educational Testing Service.

Lederman, N. G. (1986). Relating teaching behavior and classroom climate to changes in students' conceptions of the nature of science. Sci. Educ. 70, 3-19.

Lederman, N. G. (1992). Students' and teachers' conceptions of the nature of science: a review of the research. J. Res. Sci. Teach. 29, 331-359.

Lederman, N. G., Abd-El-Khalick, F., Bell, R. L., and Schwartz, R. (2002). Views of nature of science questionnaire: toward a valid and meaningful assessment of learners' conceptions of nature of science. J. Res. Sci. Teach. 39, 497-521.

Lederman, N. G., and Druger, M. (1985). Classroom factors related to changes in students; conceptions of the nature of science. J. Res. Sci. Teach. 22, 649-662.

Liang, L. L., Chen, S., Chen, X., Kaya, O. N., Adams, A. D., Macklin, M., and Ebenezer, J. (2008). Assessing preservice elementary teachers' views on the nature of scientific knowledge: a dual-response instrument. Asia-Pac. Forum Sci. Learn. Teach. 9, 1-20.

Liang, L. L., Chen, S., Chen, X., Kaya, O. N., Adams, A. D., Macklin, M., and Ebenezer, J. (2009). Preservice teachers' views about nature of scientific knowledge development: an international collaborative study. Int. J. Sci. Math. Educ. 7, 987-1012.

Liu, S., and Tsai, C. (2008). Differences in the scientific epistemological views of undergraduate students. Int. J. Sci. Educ. 30, 1055-1073.

McComas, W., Clough, M., and Almazroa, H. (1998). The role and character of the nature of science in science education. In: The Nature of Science in Science Education: Rationales and Strategies, ed. W. F. McComas, Dordrecht, The Netherlands: Kluwer Academic Publishers, 3-39.
McComas, W. F., and Olson, J. K. (1998). The nature of science in international science education standards documents. In: The Nature of Science in Science Education: Rationales and Strategies, ed. W. F. McComas, Dordecht, The Netherlands: Kluwer Academic Publishers, 41-52.

National Research Council (1997). Science Teaching Reconsidered: A Handbook. Washington, DC.: National Academies Press.

National Science Teachers Association (NSTA) (2000). NSTA Position Statement: The Nature of Science. Www.nsta.org/about/ positions/natureofscience.aspx (accessed 10 March 2009).

NSTA (2003). Standards for Science Teacher Preparation. www.nsta. org/pdfs/NSTAstandards2003.pdf (accessed 10 March 2009).

Parker, L. C., Krockover, G. H., Lasher-Trapp, S., and Eichinger, D. C. (2008). Ideas about the nature of science held by undergraduate atmospheric science students. Bull. Am. Meteorol. Soc. 89, 1681-1688.

Rubba, P. A., and Andersen, H. O. (1978). Development of an instrument to assess secondary school students understanding of the nature of scientific knowledge. Sci. Educ. 62, 449-458.

Ryan, A. G., and Aikenhead, G. S. (1992). Students' preconceptions about the epistemology of science, Sci. Educ. 76, 559-580.

Sandoval, W. A. (2005). Understanding students' practical epistemologies and their influence on learning through inquiry. Sci. Educ. $89,634-656$.

Schwartz, R. S., Lederman, N. G., and Crawford, B. A. (2004). Developing views of nature of science in an authentic context: an explicit approach to bridging the gap between nature of science and scientific inquiry. Sci. Educ. 88, 610-645.

Steyn, H. S., Jr., and Ellis, S. M. (2009). Estimating an effect size in one-way multivariate analysis of variance (MANOVA). Multivariate Behav. Res. 44, 106-129.

Stokes, M., Davis, C., and Koch, G. (2000). Categorical Data Analysis using the SAS System, Cary, NC: SAS Press.

Welch, W. W., and Pella, M. O. (1967). The development of an instrument for inventorying knowledge of the processes of science. J. Res. Sci. Teach. 5, 64-68.

Westfall, P. H., Tobias, R. D., Rom, D., Wolfinger, R. D., and Hochberg, Y. (1999). Multiple Comparisons and Multiple Tests Using the SAS System, Cary, NC: SAS Press.

Wilson, L. (1954). A study of opinions related to the nature of science and its purpose in society. Sci. Educ. 38, 159-164.

Wong, S. L., and Hodson, D. (2009). From the horse's mouth: what scientists say about scientific investigation and scientific knowledge. Sci. Educ. 93, 109-130.

Zeidler, D. L., and Lederman, N. G. (1989). The effects of teachers' language on students' conceptions of the nature of science. J. Res. Sci. Teach. 26, 771-783. 